\title{
E-LEARNING CORPORATIVO: modalidade multimétodo de avaliação de cursos de capacitação a distância
}

\author{
Iranise Alves da Silva, Dr. \\ Universidade Federal da Paraíba (UFPB)
}

\section{Magna Coely Alves da Silva}

Pensar o uso das tecnologias e redes informacionais e seus reflexos, por meio de cursos de qualificação continuada à distância sobre a força de trabalho, constitui-se apenas numa das mais pertinentes formas para proceder à análise e identificação, subsidiadas por diferentes construtos teóricos, das mudanças que vêm se configurando nas chamadas sociedades da informação e do conhecimento. No presente artigo, além de uma breve análise das questões relacionadas às mudanças que vêm se configurando nessas sociedades - também chamadas de sociedade em rede - apresentamos a modalidade multimétodo de avaliação de cursos de capacitação continuada a distância, que, além de apontar indicadores de avaliação do e-learning corporativo, vem se apresentando como uma das mais importantes alternativas metodológicas para avaliação de cursos de capacitação continuada a distância, bem como seus desdobramentos, no que se refere à significação desse processo para o desenvolvimento da força de trabalho e das organizações no Brasil.

Palavras-chave: e-learnig corporativo; capacitação continuada e a distância; modalidade multimétodo de avaliação

The use of information technology networks and their impact on the labor force by means of continued qualification at a distance is but one of the most appropriate ways of carrying out an analysis and identification all assisted by a theoretical construct - of the changes that are now occurring in our so-called informationknowledge society. It is the purpose of the present work - apart from conducting a short analysis of all the changes that are taking shape in these societies - also known as network societies - to present an evaluating multi-method modality to assess continued education courses at a distance. Such method - besides serving as a valuable indicative of corporative e-learning assessment - is regarded as one of the most significant methodological alternatives for the evaluation of continued qualification courses at a distance considering, at the same time, their impact on the improvement of both labor force and business organizations in Brazil.

Keywords: corporative e-learning; continued qualification at a distance; assessment multi-method modality

\section{Introdução}

O atual curso das sociedades contemporâneas converge para a constituição de um novo estágio de evolução na história da humanidade em que, as novas estruturas de comunicação, de cooperação e compartilhamento da mensagem, viabilizadas pelas tecnologias intelectuais inteligentes, vêm modelando as relações de tempo e espaço e promovendo verdadeiras mutações no processo de construção do saber e da inteligência coletiva.

No âmbito do modo de desenvolvimento informacional, as economias também encontram, nas modernas tecnologias de comunicação e informação, sua base de fundamentação e sustentação, pois a 
cada tipo de sociedade corresponde o uso de um tipo de máquina prevalecente na economia daquele respectivo período histórico:

- as máquinas simples ou dinâmicas - alavancas, roldanas, relógios - para as sociedades de soberania;

- as máquinas energéticas - com o perigo passivo da entropia e o perigo ativo da sabotagem para as sociedades industriais ou sociedade disciplinar';

- a cibernética e os computadores - cujo perigo passivo é a interferência, e o ativo é a pirataria e a introdução de vírus - para as sociedades das senhas e do controle, ou seja, as sociedades informacionais ${ }^{2}$.

O advento da sociedade da informação e do conhecimento tem se configurado, assim, no fundamento à construção de novas formas de organização social e produtiva, em que o intensivo uso das modernas tecnologias de informação e comunicação tem implicado a adoção de conceitos, como compartilhamento, flexibilidade, conectividade, interatividade, velocidade e simultaneidade dos processos, cujos reflexos se fazem sentir em todas as esferas da sociedade.

Nesse sentido, a instalação do ciberespaço, do espaço virtual, dos fluxos e dos nós viabilizados pelas tecnologias informacionais inteligentes inerentes às sociedades em redes, não só têm concorrido para fomentar as velozes e contínuas transformações que vêm, nessas sociedades, se registrando, como, e principalmente, têm contribuído para a emergência de verdadeiras mutações nos valores, nas tradições e nas possibilidades de construção de novas bases e laços sociais, indispensáveis à consolidação dessa nova formação econômico-social em conformação.

Reconhece-se, assim, que a tecnologia vem, historicamente, desempenhando estratégico papel, tanto nas sociedades desenvolvidas, quanto naquelas em vias de desenvolvimento, singularmente, ao fecundar uma série de inovações e avanços científicos que, em conseqüência, vão se refletir na implementação de mudanças organizacionais, institucionais, econômicas, sociais e políticas, cujas implicações e desdobramentos sócio-econômico, político e cultural nas sociedades contemporâneas vêm se manifestando, com mais veemência, a partir das últimas décadas do século XX.

Processo que vem promovendo a reestruturação do próprio capitalismo, conduzindo-o a se cristalizar num movimento de troca e acumulação através de uma espessa rede de relações econômico-digitais, virtualizando-se e, nesse bojo, estruturando as bases para o surgimento de um novo tipo de organização social: a chamada sociedade em rede, assim contextualizada por Castells (1999 ):

"é caracterizada pela globalização das atividades econômicas decisivas do ponto de vista estratégico: por sua forma de organização em redes; pela flexibilidade e instabilidade do emprego e a individualização da mão-de-obra. Por uma cultura de virtualidade real construída a partir de um sistema de mídia onipresente, interligado e altamente diversificado. E pela transformação das bases materiais da vida - o tempo e o espaço - mediante a criação de um espaço de fluxos e de um tempo intemporal como expressões das atividades e elites dominantes" (p.17).

O incremento das inovações científicas e tecnológicas que, mais intensamente, vem ocorrendo desde as ultimas décadas do segundo milênio são, em grande parte, resultantes de um novo modo de desenvolvimento econômico - o modo de desenvolvimento informacional ${ }^{3}$ - e estrutura social, em que as fontes de produtividade estão alicerçadas nas modernas tecnologias de geração de conhecimento, de processamento de informação e comunicação de símbolos.

Essas fontes estão, também, centradas na produção de bens imateriais (serviços, informações, símbolos, estéticas e valores) em substituição à produção, em larga escala, de bens materiais das sociedades dos períodos anteriores (DE MASI, 1999a). 
Faz-se necessário, portanto, compreender as implicações do uso das tecnologias e redes informacionais que, em grande parte, foram coadjuvantes dessas transformações alavancadoras do atual padrão de desenvolvimento econômico, social e educacional, também no cenário brasileiro.

Investigar os reflexos do uso das tecnologias e redes informacionais, por meio de cursos de qualificação continuada à distância sobre a força de trabalho no Brasil, constitui-se, apenas, numa das mais pertinentes formas de proceder e aprofundar análises, subsidiadas por diferentes construtos teóricos, das mudanças que vêm se configurando nas chamadas sociedades da informação e do conhecimento.

Nessa perspectiva, e tendo em vista a imperiosa necessidade de se manterem competitivas no cenário da nova ordem econômica mundial, as organizações têm despertado para o recente debate sobre as demandas por qualificação ${ }^{4}$ e formação continuada da força de trabalho.

Essas empresas acordaram para a necessidade de investir e fomentar a produção e disseminação de informação e o conhecimento, conscientes de serem esses os fatores indispensáveis à produção de bens e serviços, dentro de um conceito de padrão de qualidade, internacionalmente imposto pelo mercado econômico global.

Perceberam, também, que a flexibilidade, adaptabilidade, conectividade e velocidade constitutiva do novo paradigma organizacional priorizam aqueles processos de qualificação, treinamento e formação continuada da força de trabalho que se realizam em tempo real e no próprio espaço de trabalho. Pois, além de propiciarem redução do tempo e dos custos com os deslocamentos para a qualificação e treinamento, evitam a ausência prolongada do funcionário no ambiente de trabalho (BOLZAN, 1998). Por outro lado, possibilita que os novos conhecimentos adquiridos pelos trabalhadores tenham imediata aplicação na criação e agregação de valor aos bens e serviços produzidos, potencializando, assim, a tão almejada competitividade das organizações no cenário econômico global.

No Brasil, imbuídas desse espírito competitivo, as organizações e instituições (a exemplo de suas congêneres internacionais) também despertaram para a imperiosa e urgente necessidade de capacitar sua força de trabalho, numa perspectiva de promover treinamento, capacitação e atualização permanente dos seus conhecimentos indispensáveis, hoje, ao processo de criação e agregação de valor aos bens e serviços produzidos.

Tais premissas tornam-se cada vez mais verdadeiras, quando constatamos que, no atual cenário mundial, em constantes metamorfoses sócio-econômicas, científicas e tecnológicas, o componente intelectual de expressiva parcela das atividades econômicas elevou-se consideravelmente, aliado ao fato de que é cada vez maior, o número de trabalhadores assumindo funções que demandam maior conhecimento, maior qualificação, competência e múltiplas habilidades; exigindo deles um contínuo e permanente aperfeiçoamento que os conduza a assimilar novos valores, a desempenhar novos papéis e responsabilidades.

Além de levá-los a incorporar uma cultura de aprendizagem continuada, indispensável à permanência no atual mercado de trabalho que se define, hoje, pelo forte traço da competitividade, as organizações pretenderam, também, capacitar a sua força de trabalho para atuar em espaços físicos e/ou virtuais, equipados com as mais modernas e avançadas tecnologias (de informação e comunicação inclusive) que caracterizam, na atualidade, os ambientes de trabalho das modernas organizações.

Sem dúvida, uma gama de mecanismos faz-se presente nesse processo de qualificação à distância. Acredita-se que, simultaneamente, ocorram desdobramentos que se estendam desde a constituição de um novo perfil da força de trabalho às novas relações estabelecidas no cotidiano do contexto organizacional e institucional. 
Significa conjecturar que os resultados desses desdobramentos devem refletir-se nas relações entre o homem e a estrutura social no tempo e no espaço, ou seja, na relação de interdependência, envolvendo a ação humana e as instituições sociais.

Investigar as implicações do uso das tecnologias e redes informacionais, por meio da qualificação promovida à distância, tentando apreender os desdobramentos e repercussões desse processo para o desenvolvimento dos profissionais e das organizações foi o principal objetivo da pesquisa que deu origem aos procedimentos constitutivos da modalidade multimétodo de avaliação de cursos de capacitação continuada a distância apresentada no presente artigo.

\section{Universidades corporativas virtuais na qualificação e aprendizagem continuada da força de trabalho}

Tendo-se em conta as expectativas acima explicitadas, algumas empresas brasileiras passaram a promover treinamento e capacitação dos seus recursos humanos através das chamadas Universidades Corporativas Virtuais, utilizando o sistema de ensino à distância, suportado por modernas ferramentas das tecnologias de comunicação e informação, tais como Intranet, Internet e as multimídias interativas: $w w w$ (world wide web), audioconferência, videoconferência, IRC (internet relay chat), FAQ (frequently asked questions) correio eletrônico, telefone e fax, entre outras.

Essas ferramentas, com o suporte tecnológico de redes informacionais - a exemplo da Rede Nacional de Pesquisa - RNP ${ }^{5}$ permitem realizar, com qualidade, flexibilidade e velocidade, a educação corporativa e o respectivo processo de capacitação e treinamento da força de trabalho das organizações e instituições do país.

Para muitos estudiosos do assunto, essa nova modalidade de universidade representa, com certeza, a mobilização do setor privado na busca de alternativas que viabilizem a melhoria da performance do trabalhador e, por extensão, melhoria da performance da própria organização através da implementação de programas de formação, treinamento e qualificação da força de trabalho.

Dalmau (2001), em seu estudo sobre a importância da capacitação profissional para as empresas, definiu as universidades corporativas virtuais:

“...como uma forma encontrada pelas empresas para trabalhar e aperfeiçoar estrategicamente as competências essenciais dos seus profissionais, visando criar um padrão de excelência, além de disseminar ativamente seus valores e sua cultura organizacional."

Ainda, para esse autor, os programas de capacitação, através do Ensino a Distância, implementados pelas universidades corporativas virtuais ao maximizar o gerenciamento das informações pertinentes às atividades profissionais, propiciam maiores conhecimentos e, por extensão, um mais eficiente desempenho e motivação para trabalho dos funcionários; criam novas tendências e modificam os parâmetros das políticas de recursos humanos, além de ser parte da estratégia usada pelas empresas para atrair e reter novos talentos.

O expressivo crescimento das universidades corporativas virtuais, no processo de treinamento e capacitação da força de trabalho de considerável número de organizações e instituições, vem chamando a atenção dos pesquisadores e estudiosos para a necessidade de estudos próprios e mais acurados sobre as nuanças, especificidades e mecanismos da educação corporativa virtual implementada no seio das organizações e instituições, e os seus desdobramentos no âmbito do mercado de trabalho brasileiro.

Com essa preocupação, a pesquisa intitulada "Tecnologias e redes informacionais e suas implicações sobre a força de trabalho no Brasil", desenvolvida e analisada na tese de doutorado de igual título (SILVA, 2002), apresentada ao programa de pós-graduação da Universidade Federal de Santa 
Catarina, procurou avaliar a importância e as repercussões desse processo, tanto para a força de trabalho quanto para as organizações no Brasil.

A análise dos dados coletados na referida pesquisa, realizada junto aos profissionais integrantes dos cursos de qualificação continuada ministrados em parceria com a Universidade Federal de Santa Catarina, pelas universidades corporativas das suas respectivas organizações ${ }^{6}$, fez-se obedecendo aos procedimentos constitutivos da modalidade multimétodo de avaliação de cursos de capacitação continuada a distância (ver Figura 1), cuja operacionalização objetivou, sobretudo, a apreensão da importância e alcance, bem como dos desdobramentos e repercussões do processo de qualificação continuada on-line para o desenvolvimento da força de trabalho e para as organizações no Brasil.

Essa preocupação central da pesquisa ancorou-se nos pressupostos, segundo os quais, as tecnologias e as redes e fluxos de informação/comunicação, ao viabilizarem qualificação on-line no ciberespaço, propiciam elevação no nível da competência e formação de um novo perfil profissional, levando, conseqüentemente, à construção de novas relações e práticas sociais nas organizações brasileiras, ao tempo em que consolida o novo paradigma econômico-tecnológico no cerne da sociedade da informação e do conhecimento, também em conformação no Brasil.

\section{Modalidade de avaliação de cursos de capacitação continuada a distância}

A Modalidade Multimétodo de Avaliação de Cursos de Capacitação Continuada a Distância, apresentada a seguir, fundamenta-se numa abordagem metodológica quanti-qualitativa e estrutura-se no processo de desmontagem do discurso dos sujeitos pesquisados, recolocando os dados coletados e tratados pela técnica de Análise de Conteúdo Temática num novo contexto, que se constrói a partir do objeto e objetivos da pesquisa. Procedimento que se revela estratégico, no sentido de evitar os constrangimentos, como também os possíveis enviesamentos que as respostas diretas possam produzir às conclusões avaliativas do processo analisado.

Como sintetiza a Figura 1, A Modalidade Multimétodo de Avaliação de Cursos de Capacitação Continuada a Distância tem inicio com o tratamento dos dados coletados dos questionários, com questões objetivas e questões abertas e discursivas, aplicados aos sujeitos da pesquisa.

Para melhor entendimento do procedimento da análise de conteúdo sobre os dados qualitativos das questões discursivas, serão apresentadas, a seguir, algumas considerações teóricas sobre a referida técnica.

\begin{tabular}{|l|l|}
\hline LEVANTAMENTO DIAGNÓSTICO & $\begin{array}{l}\text { Aplicação de questionários, com questões objetivas e questões abertas e } \\
\text { discursivas. }\end{array}$ \\
\hline TRATAMENTO DOS DADOS & $\begin{array}{l}\text { Aplicação da técnica de Análise de Conteúdo Temática e do software } \\
\text { SPSS no tratamento dos dados coletados. }\end{array}$ \\
\hline DESCONSTRUÇÃO DO DISCURSO & $\begin{array}{l}\text { Com base nos parâmetros da técnica de Análise de Conteúdo Temática, } \\
\text { inventariar e recortar as falas dos sujeitos pesquisados. }\end{array}$ \\
\hline RECONSTRUÇÃO DO DISCURSO & $\begin{array}{l}\text { Categorização, subcategorização e respectivo agrupamento das } \\
\text { unidades temáticas de análise na reconstrução do discurso dos sujeitos } \\
\text { pesquisados. }\end{array}$ \\
\hline AVALIAÇÃO FINAL & $\begin{array}{l}\text { Elaboração do relatório de avaliação do processo de capacitação on-line } \\
\text { a partir do discurso reconstruído com base nos resultados da Análise de } \\
\text { Conteúdo Temática e da aplicação do SPSS. }\end{array}$ \\
\hline
\end{tabular}

Figura 1 - Modalidade multimétodo de avaliação de Cursos de capacitação continuada a distância Fonte: Silva (2002) 


\section{A Técnica de Análise de Conteúdo - considerações teóricas}

Para compreensão da análise de conteúdo selecionada (temática) faz-se imprescindível apresentarmos algumas considerações teóricas:

A análise de conteúdo vem, durante muito tempo, sendo apresentada como uma técnica predominantemente útil no estudo da comunicação social e da propaganda política associada a objetivos programáticos e de intervenção. Nesse sentido, é tida como uma das mais eficientes técnicas para análise de toda e qualquer forma de comunicação (oral, visual, escrita, sonora), ou seja, uma eficiente técnica de análise utilizada para decodificar mensagens e suas significações latentes, ocultas e manifestas, resgatadas de diferentes e variadas fontes documentais.

Hoje, segundo Vala (1986), a técnica de análise de conteúdo é, sobretudo, considerada uma das técnicas mais utilizadas na investigação empírica realizada pelos diferentes campos das ciências sociais e humanas. O referido autor destaca, de maneira sumária, algumas definições de análise de conteúdo, dentro de uma seqüência cronológica, a de Berelson (1952), Cartwright (1953), Krippendorf (1980) e ainda a de Bardin (1991).

Para Berelson (1952), a análise de conteúdo constitui-se numa descrição objetiva, sistemática e quantitativa do conteúdo manifesto da comunicação. Cartwright (1953) amplia o alcance dessa definição a todo comportamento simbólico. Por sua vez, Krippendorf (1980) define a análise de conteúdo como uma técnica de investigação que viabiliza inferências válidas dos dados possíveis de serem reaplicáveis no seu contexto.

Entre essas definições, destaca-se a importante definição de Bardin (1991), quando afirma ser a análise de conteúdo "um conjunto de técnicas de análise das comunicações visando obter, por procedimentos, sistemáticos e objetivos de descrição do conteúdo das mensagens, indicadores (quantitativos ou não) que permitem a inferência de conhecimentos relativos às condições de produção/recepção (variáveis inferidas) destas mensagens".

Para Vala (1986), as abordagens conceituais sobre a análise de conteúdo, elaborada pelos diferentes autores, acima referenciados, revela "o caráter objetivo e sistemático da análise de conteúdo referido por Berelson e Cartwright e as condições de validade e reaplicabilidade expressa por Krippendorf. Ainda para esse autor, a análise de conteúdo, enquanto técnica de pesquisa, exige a maior explicitação de todos os procedimentos utilizados" (Vala,1986, p.103).

Em síntese, argumenta Vala (1986), enquanto analisa o discurso e suas condições de produção, a técnica de análise de conteúdo permite, articulando-os com o contexto no qual o discurso foi produzido, efetuar inferências sobre as mensagens inventariadas e sistematizadas.

Neste sentido, evocam-se as idéias de Vala (1986), segundo as quais, para se operacionalizar a técnica de análise de conteúdo temática, optar-se-á pela unidade de registro, por ser uma unidade que contempla também a unidade semântica, na qual a mais comum é o tema ou unidade de informação, o que poderá ou não coincidir com unidades lingüísticas. Além do mais, a opção pela unidade de registro faz-se, principalmente, objetivando-se revelar a atenção dada às falas dos sujeitos pesquisados, conferindo-lhes diferentes conteúdos inventariados, o que vai, por meio dessa análise, viabilizar inferências sobre a organização do sistema de pensamento e expressão desses sujeitos.

Nessa perspectiva, e a partir dos preceitos teórico-metodológicos propostos, foi, na presente investigação, utilizada a análise de conteúdo, seguindo-se as seguintes etapas operacionais:

a) constituição do corpus;

b) composição das unidades de análise;

c) procedimentos de análise (codificação e recortes);

d) categorização e

e) tratamento / validação dos resultados. 


\section{a) Constituição do corpus}

O corpus é constituído pelos questionários aplicados aos profissionais integrantes da amostragem selecionada.

\section{b) Composição das unidades de análise}

Após a leitura flutuante do corpus e as definições das categorias e subcategorias simbólicas emergentes (empíricas), foram estas, respectivamente codificadas.

Para a escolha das unidades de análise, esta técnica baseou-se na abordagem de Vala (1986). Em sua abordagem, geralmente, só existem dois tipos de unidades: formais e semânticas. As unidades formais incluem palavras, frases, um personagem ou a intervenção do locutor; as unidades semânticas compreendem o tema ou a unidade de informação.

Neste estudo, optou-se pelas unidades de contexto, que, segundo definições do referido autor, são compreendidas pelos segmentos mais largos de conteúdo, ou melhor, são os temas maiores das entrevistas, e os temas que emergiram dos questionários foram decompostos em unidades de análise temáticas e, posteriormente, em temas semânticos mais simples.

\section{c) Codificação e recortes}

Após a decomposição do corpus e a codificação dos temas, agrupou-se o material em subcategorias e categorias simbólicas.

\section{d) Categorização}

O corpus foi agrupado em cinco conjuntos de categorias simbólicas e quinze subcategorias

\section{e) Validação dos resultados}

Após as definições das categorias e subcategorias simbólicas emergentes (empíricas), foram estas codificadas e validadas internamente por dois professores que trabalham com o mesmo referencial teórico-metodológico, ou seja, com a técnica de Análise de Conteúdo Temática.

\section{0 uso do Statistical Package for Social Science}

Selecionou-se o programa Microsoft Access (banco de dados relacional) para a construção de um banco de dados para as questões fechadas e abertas do respectivo questionário, onde as informações coletadas foram tratadas pelo pacote estatístico SPSS (Statistical Package for Social Science) - em que as variáveis estudadas foram mensuradas nos níveis das escalas nominal, ordinal e intervalar.

Verificou-se, inicialmente, com o uso do SPSS, a consistência das informações, efetuando-se a recodificação de algumas variáveis. Em seguida, procedeu-se à análise estatística por meio da construção de tabelas de freqüências e cruzamentos das variáveis pertinentes, para o levantamento do perfil dos pesquisados, objetos de estudo.

Na seqüência, e de acordo com objetivos específicos propostos, tabelas de freqüências auxiliaram na confecção de quadros para classificação em ordem de prioridade de algumas variáveis pertinentes. As categorias identificadas na Análise de Conteúdo (Bardin,1991) foram adicionadas ao arquivo SPSS para complementação da análise estatística dessas categorias.

Portanto, num segundo momento da operacionalização dessa modalidade, o discurso é reconstruído atribuindo-lhe traços de significação através do processo de inferência da lógica explicitada na mensagem inventariada e sistematizada pela técnica de Análise de Conteúdo Temática. 
Conjuntamente com os resultados estatísticos dos dados tratados pelo software Statistical Package for Social Science - SPSS, constrói-se então, o relatório final que vai expressar a avaliação dos sujeitos pesquisados em relação aos cursos de capacitação continuada e a distância, promovidos pelas respectivas organizações.

Esses procedimentos, além de expressar a originalidade da proposta metodológica para estudos dessa natureza, representam uma relevante contribuição aos processos de avaliação de cursos de capacitação continuada a distância, realizados no âmbito organizacional.

\section{Alguns resultados da pesquisa}

Da operacionalização dos procedimentos da modalidade multimétodo de avaliação de cursos de capacitação continuada a distância, melhor dizendo, do tratamento (pela técnica da análise de conteúdo) dos dados qualitativos dos questionários aplicados, emergiram cinco categorias e quinze subcategorias simbólicas, respectivamente, conforme apresentado na Figura 2.

No caso da pesquisa referenciada nesse artigo, os resultados da operacionalização dessa modalidade multimétodo de avaliação de cursos de capacitação continuada e a distância, não só apontaram as categorias e sub-categorias, referenciadas, indicadores de avaliação do e-learning corporativo, como mostraram algumas das mais importantes implicações do uso das tecnologias e redes informacionais por meio dos de cursos de capacitação continuada a distância, bem como seus desdobramentos, no que se refere à significação desse processo para o desenvolvimento da força de trabalho e das organizações no Brasil.

\begin{tabular}{|c|c|c|c|}
\hline CATEGORIAS & SUBCATEGORIAS & $\begin{array}{l}\text { CODIFICAÇÃO: } \\
\text { CATEGORIAS } \\
\text { SUBCATEGORIAS }\end{array}$ & $\begin{array}{ll}\text { NÚMERO } & \text { DE } \\
\text { UNIDADES } & \text { DE } \\
\text { ANÁLISE } & \end{array}$ \\
\hline Tipos de sistemas & $\begin{array}{l}\text { Sistema a Distância } \\
\text { Sistema Presencial } \\
\text { Sistema Misto } \\
\text { (Distância/Presencial) }\end{array}$ & $\begin{array}{l}\text { TSD } \\
\text { TSP } \\
\text { TSM }\end{array}$ & $\begin{array}{l}69 \\
35 \\
32\end{array}$ \\
\hline $\begin{array}{l}\text { Modalidade } \\
\text { de práticas }\end{array}$ & $\begin{array}{l}\text { Interacional } \\
\text { Individual } \\
\text { Facilitadora }\end{array}$ & $\begin{array}{l}\text { MPI } \\
\text { MPID } \\
\text { MPF }\end{array}$ & $\begin{array}{l}39 \\
16 \\
85\end{array}$ \\
\hline Atitudes & $\begin{array}{l}\text { Favorável } \\
\text { Desfavorável } \\
\text { Neutra }\end{array}$ & $\begin{array}{l}\text { AF } \\
\text { AD } \\
\text { NA }\end{array}$ & $\begin{array}{l}49 \\
97 \\
19\end{array}$ \\
\hline Motivação & $\begin{array}{l}\text { Profissional } \\
\text { Institucional }\end{array}$ & $\begin{array}{l}\text { MP } \\
\text { MI }\end{array}$ & $\begin{array}{l}77 \\
36\end{array}$ \\
\hline $\begin{array}{l}\text { Tipos } \\
\text { de necessidades }\end{array}$ & $\begin{array}{l}\text { Recursos Humanos } \\
\text { Recursos Materiais } \\
\text { Ambientais }\end{array}$ & $\begin{array}{l}\text { TNRH } \\
\text { TNRM } \\
\text { TNA }\end{array}$ & $\begin{array}{l}14 \\
23 \\
6\end{array}$ \\
\hline
\end{tabular}

Figura 2 - Distribuição das categorias e subcategorias simbólicas

Ressalte-se, entre as conclusões a que chegou o presente estudo, a concretização de novas práticas sociais interacionais e facilitadoras rotinizadas pela força de trabalho, e como práticas resultantes do uso das tecnologias e redes informacionais nos cursos de capacitação continuada, como uma das mais importantes experiências vivenciada no cotidiano de trabalho, pelos sujeitos pesquisados. 
Ainda no âmbito da interação social, também foram identificadas transformações nos profissionais pesquisados, balizadas pelo viés da qualificação da força de trabalho on-line no ciberespaço, tais como: atitudes favoráveis, fortalecimento de princípios e valores, como espírito de cooperação, solidariedade, sociabilidade, capacidade de escolhas e espírito de participação em eventos e trabalhos de equipe, sensivelmente identificados como resultantes da capacitação continuada, utilizando as modernas tecnologias e redes informacionais.

Em relação às mudanças percebidas, tanto pelos profissionais quanto pelas organizações em face da realização dos referidos cursos de qualificação continuada e a distância, destacam-se como mais importantes, numa ordem de prioridade definida pelos sujeitos pesquisados: $1^{\circ}$ - Desempenho pessoal $(93,7 \%) ; 2^{\circ}$ - motivação e desempenho no trabalho $(88,5 \%) ; 3^{\circ}$ - qualidade do produto/serviço produzido $(86,7 \%)$ e $4^{\circ}$ - imagem pessoal na organização $(76,6 \%)$, fatores que não só evidenciam uma elevação no nível de qualificação do trabalhador, como, e principalmente, refletem-se diretamente na produtividade e qualidade do serviço e/ou produto produzido pelas organizações em questão.

No tocante às formas de repercussão do processo em análise, amplamente descritas no decorrer da presente investigação revelaram-se como mais importantes, também numa ordem de classificação definida pelos pesquisados: $1^{\circ}$ - auto-estima pessoal; $2^{\circ}$ - auto-estima profissional; $3^{\circ}$ - reconhecimento profissional; $4^{\circ}$-integração e $5^{\circ}$ - valorização profissional e competitividade.

Esses dados expressam, sobretudo, que a realização dos cursos de capacitação continuada no âmbito organizacional, favorece o reconhecimento profissional pelos superiores hierárquicos e pelos colegas de trabalho, estimula o processo de integração laboral e social do trabalhador nas atividades desenvolvidas pela organização, propicia maior valorização e, conseqüentemente, maior satisfação no trabalho, elementos fundamentais ao florescimento de um clima de criatividade, melhor desempenho e maior compromisso do trabalhador para com o desenvolvimento da organização.

No que diz respeito ao questionamento quanto aos benefícios auferidos em função da realização dos cursos, ora em análise, $72 \%$ dos pesquisados afirmaram terem auferido alguma forma de benefício em função da realização dos cursos de capacitação continuada. Ainda no tocante às formas de benefícios auferidos, foi surpreendente a escolha de $77,1 \%$ dos pesquisados, que elegeram o desenvolvimento de atividades mais importantes e de maior nível de complexidade e abstração como o mais importante benefício auferido em face da realização dos cursos em análise, numa clara demonstração da tomada de consciência desses profissionais, quanto à necessidade da permanente atualização dos seus conhecimentos como condição indispensável para permanecerem inseridos, com competência e competitividade, no exigente mercado de trabalho dos dias atuais.

Em relação ao significado, para o trabalhador, de realizar os referidos cursos com uso das modernas tecnologias e redes informacionais, foi declarado pela expressiva maioria dos pesquisados (94\%) ser importante $(32,8 \%)$ e muito importante $(61,2 \%)$, respectivamente, a permanente atualização dos seus conhecimentos através dos cursos de capacitação continuada a distância. Avaliações essas, que fundamentaram a escolha do total de $82,1 \%$ dos pesquisados quanto à modalidade de ensino a distancia $(35,8 \%)$ e misto $(46,3 \%)$, respectivamente, como preferência dos profissionais quanto à realização de cursos de qualificação continuada, no âmbito das suas respectivas organizações.

Essa expressiva preferência fundamenta-se nos argumentos, segundo os quais, ao fazerem amplo uso de modernas tecnologias de informação e comunicação, no decorrer dos referidos cursos, os profissionais envolvidos no processo vão, também, minimizar as dificuldades que afetam, hoje, expressiva parcela dos trabalhadores que ainda não desenvolveram habilidades e desenvoltura no trato com a informática.

Portanto, como resultado das conclusões apresentadas, infere-se que o processo de capacitação continuada e a distância, promovido pelas organizações, em parcerias com renomadas e respeitadas instituições públicas de ensino, contribui, efetivamente, para o desenvolvimento, tanto dos profissionais quanto das organizações no Brasil. 
1- Foucault (1999) conceitua e analisa a sociedade disciplinar e de controle social via confinamento característica do capitalismo industrial estruturado na exploração do trabalho, concentrado nas fábricas e nas empresas que, por sua vez, condiciona a existência de outras formas de instituições de confinamento social (escola, hospital...).

2- Deleuze (1992) analisa a sociedade informacional - sociedade das senhas e do controle, em que os mecanismos de resistência e de controle são abertos, conectados e contínuos em rede, em face da característica de mobilidade, velocidade e fluidez viabilizada pelas mutações tecnológicas, enquanto atributo do processo de desterritorialização patrocinado pelo novo capitalismo informacional virtualizado.

3- Para Silva (2002), o modo de desenvolvimento informacional, também denominado de capitalismo informacional, é, como concreção histórica, o sistema de produção em que a informação e o conhecimento são focalizados como principal elemento de criação e agregação de valor aos bens e serviços produzidos com qualidade, segundo os padrões internacionalmente estabelecidos.

4- $O$ conceito de qualificação do trabalhador aglutina, de forma mais ampla, um conjunto de saberes: escolar, técnico e social, que o capacita profissionalmente. Noção essa que envolve diferentes dimensões, sendo a mais importante, segundo Keorgat (1987), a da capacitação como relação social que se estabelece na construção histórica da relação capital /trabalho.

5- As informações sobre a rede nacional de pesquisa - RNP encontram-se nos sites: http://www.rnp.br e http://www.socinfo.org.br

6 - As organizações pesquisadas foram: EMBRAPA - Empresa Brasileira de Pesquisa Agropecuária; PETROBRÁS - Petróleo Brasileiro S.A.; CEFET-RN - Centro Federal de Educação Tecnológica do Rio Grande do Norte; PUC - Pontifícia Universidade Católica de Goiás; UEM -Universidade Estadual de Mato Grosso; FUNCABE - Fundação Educacional "Presidente Castelo Branco"; FAMIH Faculdades Metodistas Integradas Izabela Hendrix -; Fiat Automóveis S.A.( A Fiat só enviou a avaliação do executivo/coordenador do programa de educação coorporativa e um rico material informativo sobre a Universidade Corporativa e Virtual da empresa.

\section{Referências}

BARDIN, Laurence. Análise de conteúdo. Lisboa: Edições 70, 1991.

BEMFICA, Juliana do Couto; BORGES, Mônica Erichsen Nassif. Aprendizagem organizacional e informação. Revista Ciência da Informação. Brasília, v. 28, n. 3, p. 233-240, set./dez. 1999

BENIGER, J.R. The control revolution: technological end economic origins of the information society. Cambridge, MA, e Londres: Harvard University Press, 1986

BENKO, Georges. Economia, espaço e globalização. São Paulo: Hucitec, 1996.

BERELSON B. Content analisys in communication research. N.York: Free Press,1952

BORGES, Mônica Erichsen Nassif. A informação como recurso gerencial das organizações na Sociedade da Informação. Revista Ciência da Informação. Brasília, v. 24, n. 2, 1995.

BOLZAN, Regina de F.F. de Andrade. O conhecimento tecnológico e o paradigma educacional. Florianópolis, UFSC/PPGEP, 1998. (Dissertação de Mestrado) 
CASTELLS, Manuel. A era da informação: economia sociedade e cultura: a sociedade em rede. São Paulo: Paz e Terra 1999.

CARTWRIGTH, D.P. Analysis of qualitative material . In: Festinger, L; Katz, D.(eds). Research methods in the behavioral sciences, N.York: HoLT, 1953

DELEUZE, G. Conversações. Rio de Janeiro: edt. 34, 1992.

DE MASI, Domenico. O futuro do trabalho - fadiga e ócio nas sociedades pós-industriais. Rio de Janeiro: UNB/José Olímpio. 1999.

A sociedade pós industrial, $2^{\text {a }}$.ed. São Paulo: SENAC, 1999a.

DALMAU, Marcos B. Lopes. Impactos da utilização da EAD na capacitação de Recursos Humanos em empresas de grande porte. Florianópolis: UFSC/PPGEP, 2001 (dissertação de mestrado).

DAVENPORT, Tomas H; PRUSAK, Laurence. Conhecimento empresarial: como as organizações gerenciam seu capital intelectual. Rio de Janeiro: Campus, 1998.

EDWARDS, Richard; USHER, Robin. Globalization and a pedagogy of (dis)location. http://www.leeds.ac.uk/educol/documents/000000225.htm . Acessado em 04 nov. 2000.

FOUCAULT, Michel. Microfisica do Poder. Rio de Janeiro, Graal,1999

KERGOAT, D. Em defesa de uma sociologia das relações sociais - da análise crítica das categorias à elaboração de uma nova conceituação. In: O sexo no trabalho. São Paulo: PAZ E Terra, 1987.

KIPPENDORFF, Klaus. Content analysis: an introducion to its methodology. Londres: SAGE, 1980.

MEISTER, Jeanne C. Educação corporativa - a gestão do capital intelectual através das universidades corporativas. São Paulo: Makron Books,1999.

NONAKA, I; TAKEUCHI, H. Criação do Conhecimento na Empresa - Como as empresas Japonesas geram as dinâmica da inovação . Rio de Janeiro: Campus, 1997.

SENGE, Peter M. The leader's new work: building learning organization. Sloan Management Review, 1990.

SHAMIR, Boas; Salomon, Ilan. Work-at-home and the quality of working life. Academy of Management Review, v. 10, no. 3, p. 455-464, 1985.

SILVA, Iranise Alves. Tecnologia e redes informacionais e suas implicações sobre a força de trabalho no Brasil. Florianópolis, Programa de Pós Graduação em Engenharia da Produção - UFSC, 2002.

SILVA, Iranise Alves; CELLA, Carmem Rejane. Tecnologias de informação e a organização do teletrabalho. Revista P\&S, Produção e Sociedade, João Pessoa, nº.4, p.55-76, novembro /1999.

STWART, T. Intellectual Capital. Currency-Doubleday, New York, 1997

SVEIBY, Karl Erik. The new organization wealth: Managing and measuring knowledge-based assest. San Francisco: Berrett-Koehler Publishers. 
SVIOKLA, John J. Knowledge workers and radically new technology. Sloan Management Review, vol. 37, n.4 p 25-40 summer, 1996.

TOURAINE, Alain. La société post-industrielle. Paris: Denoel, 1969.

VALA, Jorge. A análise de conteúdo. In: SILVA, Augusto Santos; Pinto, José Madureira (org). Metodologia da Ciências Sociais. Lisboa: Afrontamento, 1986.

VALDEMIR, et al. Integração universidade-empresa: passaporte para o futuro. In: Seminário Tecnologias da Informação e Comunicação em Educação a distância- LDB”, Rio de Janeiro, 1997. (a) 